九州大学学術情報リポジトリ

Kyushu University Institutional Repository

\title{
The Dependence of Magnetic Bays and the Main Phase of Magnetic Storms on Magnetic Latitude and Local Time
}

Sun, W.

Geophysical Institute, University of Alaska Fairbanks

Shiokawa, Kazuo

Solar-Terrestrial Environment Laboratory, Nagoya University

Yumoto, Kiyofumi

Faculty of Sciences, Kyushu University

Kitamura, Tai ichi

Faculty of Sciences, Kyushu University

他

https://doi.org/10.5109/1546092

出版情報: 九州大学大学院理学研究院紀要 : Series D, Earth and planetary sciences. 30 (2)， pp.71-80, 1998-12-28. 九州大学大学院理学研究院

バージョン :

権利関係 : 
Mem. Fac. Sci., Kyushu Univ., Ser. D, Earth \& Planet. Sci., Vol. XXX, No.2, pp. 71-80, text-figs. 1-8, table 1, December 28, 1998

\title{
The Dependence of Magnetic Bays and the Main Phase of Magnetic Storms on Magnetic Latitude and Local Time
}

\author{
W. Sun*, K. ShiokaWA**, K. Yumoto, T.-I. Kitamura, J.V. Olson* \\ and S.-I. AKasofu*
}

\begin{abstract}
Magnetic records from the $210^{\circ}$ magnetic meridian stations between July, 1992 and June, 1993 are examined to study the dependence of magnetic bays and the main phase of magnetic storms on magnetic latitude and local time (MLT). The results show that the magnitude of bays in the $\mathrm{H}$ component at mid and low latitudes is weakly dependent on the latitude. As many earlier studies show, the peak of the occurrence frequency of bays in the $\mathrm{H}$ component is located at 21-0 MLT. Positive bays in the $\mathrm{H}$ component occur most frequently around the midnight sector; negative bays in the $\mathrm{H}$ component occur most frequently in the evening sector. The magnitude of bays in the $\mathrm{D}$ component depends grealty on the latitude. The peak of the occurrence frequency of bays in the $\mathrm{D}$ component is also located at 21-0 MLT. Positive bays in the D component most frequently occur in the late evening sector and negative bays in the $\mathrm{D}$ component most frequently occur in the early morning sector. The dependence of the magnitude of magnetic bays on the latitude calculated by a model of three-dimensional current system at high latitudes is in fair agreement with the statistical results.

The magnitude of the main phase decrease along the meridian has the minimum located at about $30^{\circ}$ magnetic latitude. As many earlier studies show, the maximum magnitude of the main phase decrease most frequently occur at 21-0 MLT.
\end{abstract}

\section{Introduction}

The main phase of magnetic storms and magnetic bays are typical magnetic variations observed at mid- and low-latitudes. As is well known, magnetic bays observed at mid-and low latitudes are closely related to the substorm activity (SilsbeE and Vestine, 1942; Fukushima, 1953; Akasofu and Meng, 1969; Meng and Akasofu, 1969; Clauer and McpherRON, 1974), and are mainly produced by the three-dimensional current system during substorms (KAMIDE et al., 1981; Sun et al., 1984).

The main phase of the magnetic storm is defined as the depression of the horizontal component of geomagnetic field on the surface of the earth (CHAPMAN, 1919). The development of the main phase is attributed to the development of the ring current which is formed by the drift of the trapped particles in the inner magnetosphere (e.g. AKASOFU and CHAPMAN,

\footnotetext{
Manuscript received August 17, 1998; accepted September 21, 1998.

* Geophysical Institute, University of Alaska Fairbanks, Fairbanks, Alaska 00775, USA

* Solar-Terrestrial Environment Laboratory, Nagoya University, Toyokawa 442-8507, Japan
} 
1961). The Dst index is devised to monitor the symmetric (average) ring current (SUGIURA, 1964).

The $210^{\circ}$ magnetic meridian (MM) network project started in 1990 as one of Japanese STEP projects (YUMOTO et al., 1992, 1996). More than twenty observatories along the $210^{\circ}$ MM cover the latitudinal range from the auroral zone to the equator in both the northern and southern hemispheres. The extensive magnetic observations along such a magnetic meridian enable us to advance our knowledge for magnetic storms, substorms and the relationship between them. In the present work, we study the dependence of the magnetic bays and the main phase of magnetic storms on magnetic latitude and local time, using the extensive magnetic observations along the $210^{\circ} \mathrm{MM}$. The magnetic perturbations at mid- and lowlatitudes calculated by a model of three-dimensional current system are compared with the statistical results from the $210^{\circ} \mathrm{MM}$ data.

\section{Date and Results}

We select nine stations in the northern hemisphere from the $210^{\circ} \mathrm{MM}$ network; they are distributed from the auroral latitude to the equator. The names and the geomagnetic latitudes of stations are listed in Table 1.

Table 1. The name and the magnetic latitude of stations

\begin{tabular}{|l|l|c|}
\hline Name & Code & Magnetic Latitude \\
\hline Chokurdakh & CHD & $64.75^{\circ}$ \\
\hline Magadan & MGD & $53.70^{\circ}$ \\
\hline St. Paratunka & PTK & $46.49^{\circ}$ \\
\hline Moshiri & MSR & $37.76^{\circ}$ \\
\hline Onagawa & ONW & $31.79^{\circ}$ \\
\hline Kagoshima & KAG & $25.23^{\circ}$ \\
\hline Chichijima & CBI & $20.65^{\circ}$ \\
\hline Guam & GUA & $9.02^{\circ}$ \\
\hline Yap & YAP & $-0.83^{\circ}$ \\
\hline
\end{tabular}

The magnetometer data observed at the nine stations from August 1992 to May 1993 are employed to examine the latitudinal dependence of the magnetic bays and the main phase of magnetic storms.

\subsection{Bays in the $\mathrm{H}$ and the $\mathrm{D}$ component}

Total 181 bays in the $\mathrm{D}$ component and 154 bays in the $\mathrm{H}$ component during the ten months are examined. Fig. 1 shows an example of bays in the $H$ and $D$ component observed at nine stations on February 8, 1993. Three substorm events can be clearly seen from $\mathrm{H}$ component variations observed at the high-latitude station, CHD. The occurrence of positive bays in the $\mathrm{H}$ component ( $\mathrm{H}$ bays) is well correlated to the substorm events. However, the magnitude of the positive $\mathrm{H}$ bays does not appear to be proportional to the magnitude of negative $\mathrm{H}$ component perturbations recorded at $\mathrm{CHD}$. This kind of magnetic $\mathrm{H}$ component peiturbations at high latitudes is known to be produced by the auroral electrojet during 


\section{MM Magnetic Field Data 250nT/div(CHD), 50nT/div(Others)}

Feb 8, 1993
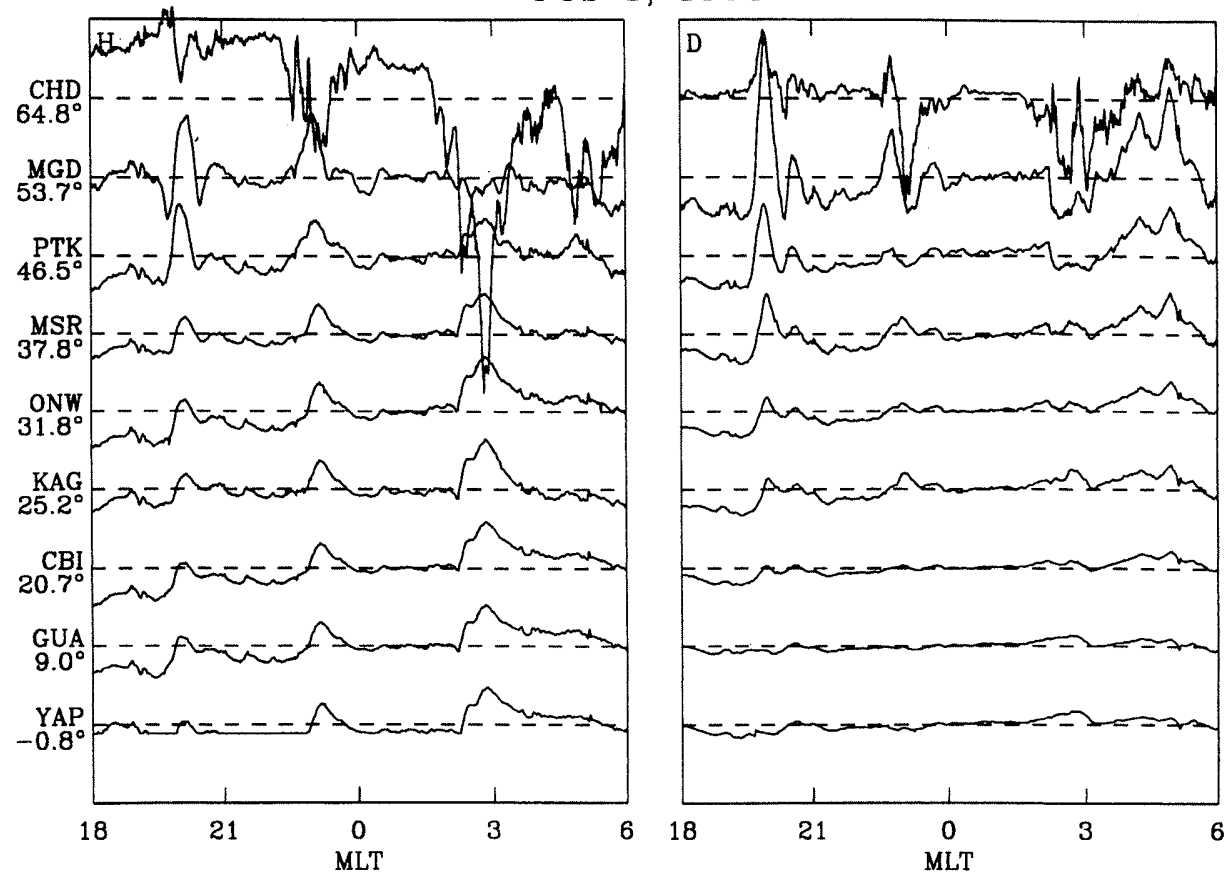

Fig. 1. $\mathrm{H}$ and $\mathrm{D}$ component variations of magnetic field observed at nine stations along the $210^{\circ} \mathrm{MM}$ during $18 \sim 6 \mathrm{MLT}$ on February 8 , 1993. The bay disturbances can be clearly seen in the $\mathrm{H}$ and $\mathrm{D}$ component traces.

substorms. We note also that the magnitude of bays in the $\mathrm{D}$ component ( $\mathrm{D}$ bays) is greatly dependent on latitude, but the magnitude of $\mathrm{H}$ bays is not.

Fig. 2 shows the statistical dependence of the magnitude of magnetic bays on magnetic latitude. The magnitude of magnetic bays is normalized by the magnitude of bays observed at GUA at magnetic latitude of $9^{\circ}$. The black dots indicate the data points. The solid curves show the fitted results for the positive and the negative bays in the $\mathrm{H}$ and the $\mathrm{D}$ components, respectively. The fitted results can be formulated as the following:

$$
\begin{aligned}
& B^{+}{ }_{H}=0.0011 \lambda^{2}-0.0344 \lambda+1.0878 \\
& B^{-}{ }_{H}=-0.0014 \lambda^{2}+0.0524 \lambda-1.5153 \\
& B^{+}{ }_{D}=0.0046 \lambda^{2}-0.0971 \lambda+1.5448 \\
& B^{-}{ }_{D}=-0.0049 \lambda^{2}+0.1259 \lambda-1.8274
\end{aligned}
$$

where $\mathrm{B}$ is the normalized magnitude, as mentioned above; the symblo "+ " and "- " indicate the positive and negative bay, respectively, and " $H$ " and " $D$ " for the $\mathrm{H}$ and $\mathrm{D}$ component; $\lambda$ is the magnetic latitude.

We estimate that the minimum magnitude of $\mathrm{H}$ bays is located at $15^{\circ} \sim 18^{\circ}$ magnetic latitude and the minimum magnitude of $\mathrm{D}$ bays at $10^{\circ} \sim 12^{\circ}$. The magnitude of $\mathrm{H}$ bays at $50^{\circ}$ 

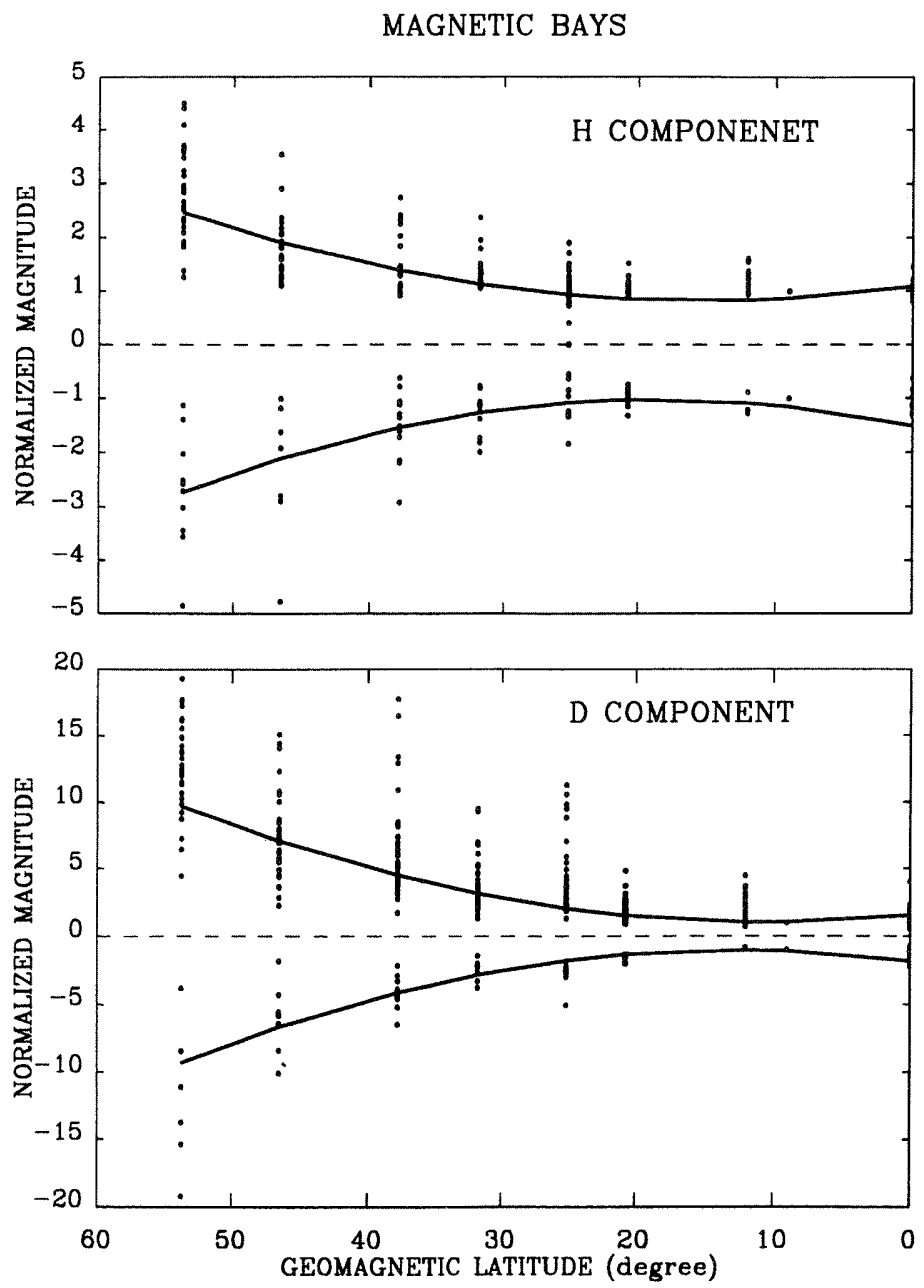

Fig. 2. The statistical dependence of magnetic bays on magnetic latitude. The black dots show the date points. The solid curves are fitted from the data points.

magnetic latitude is two times larger than that at $10^{\circ}$, and the magnitude of $\mathrm{D}$ bays at $50^{\circ}$ is found to be 8 times larger, as statistical results shown in Fig. 2.

Fig. 3 shows the statistical dependence of the occurrence frequency of magnetic bays on magnetic local time. The maximum occurrence frequency of both $\mathrm{H}$ bays and $\mathrm{D}$ bays is in the $21 \sim 0$ MLT sector. The positive $\mathrm{H}$ bays mostly occur in the midnight sector and the negative $\mathrm{H}$ bays in the evening sector. This is consistent with the distribution of the westward and eastward electrojet along with the MLT during substorms. Posivite D bays occur mostly in the premidnight sector and negative $\mathrm{D}$ bays in the morning sector. This distribution is associated with the distribution of the field-aligned currents in the substorm current wodge, where the field-aligned currents flow into the ionosphere in the morning sector and flow out in the premidnight sector (MCPHERRON et al., 1973). 

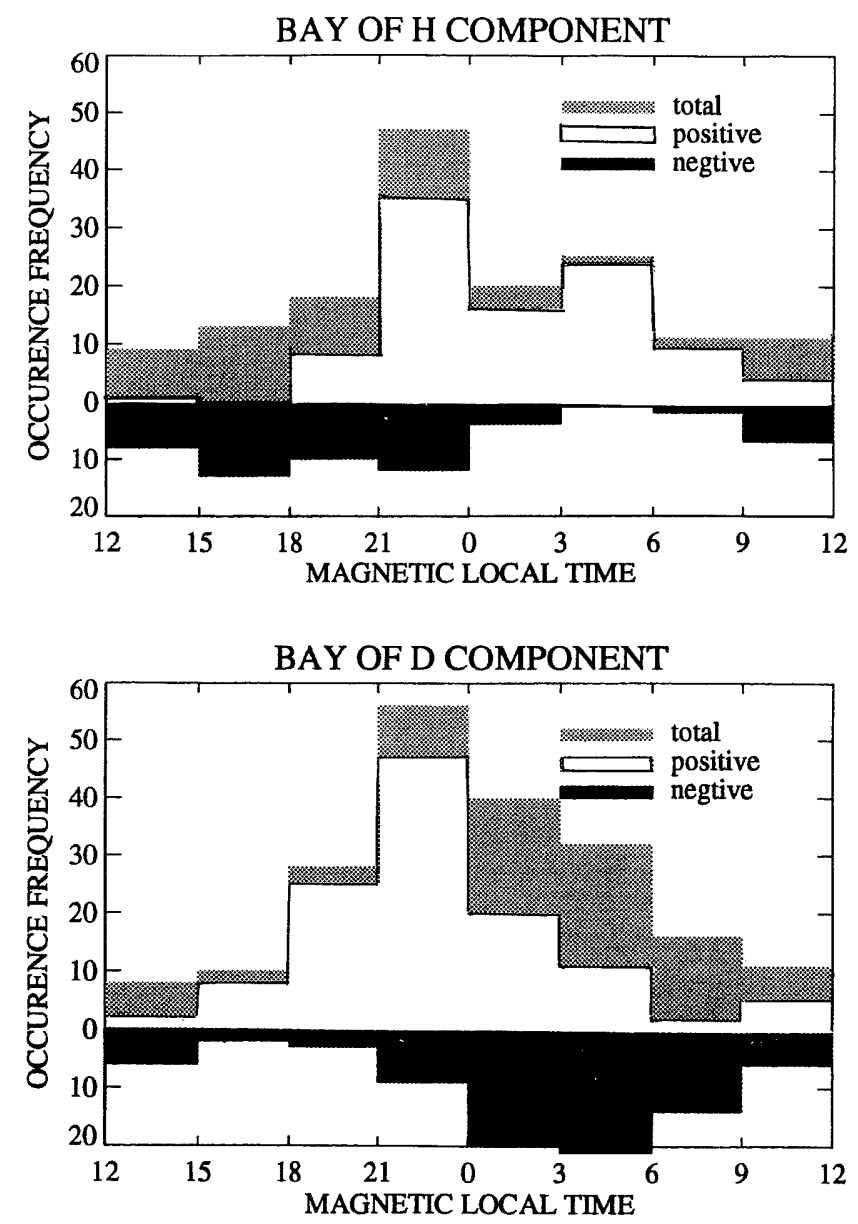

Fig. 3. The statistical distribution of the occurrence frequency of magnetic bays along the $210^{\circ} \mathrm{MM}$ stations with magnetic local time.

\subsection{The main phase of magnetic stoms}

Thirty storm events are examined to obtain the statistical dependence of the magnitude of the mian phase of magnetic storms on mgnetic latitude during ten months. Fig. 4 shows an example of $\mathrm{H}$ and $\mathrm{D}$ component variations recorded at nine stations during the magnetic storm of March 15, 1993. The minimum value of the Dst index is - $91 \mathrm{nT}$ for this storm event. The development of the main phase of this storm occurs from 16 22 MLT. The intense positive D bays occur at $18 \mathrm{MLT}$ and $20 \mathrm{MLT}$, and indicate the existence of the intense upward field-aligned currents during the main phase. We note also that an intense positive $\mathrm{H}$ bay occurs at 22 MLT.

The statistical dependence of the magnitude of the main phase on latitude is shown in Fig. 5. The magnitude of the main phase (was defined) by the minimum value of negative $\mathrm{H}$ cxomponent variations during the main phase of storms. The magnitude of the main phase is normalized by the minimum value of the Dst index during the storms. In Fig. 5, black dots indicate the data points and the solid curve is the fitted result. It is interesting that the 
210 MM Magnetic Field Data $500 \mathrm{nT} / \operatorname{div}(\mathrm{CHD}), 100 \mathrm{nT} / \operatorname{div}$ (Others)

MARCH 15, 1993
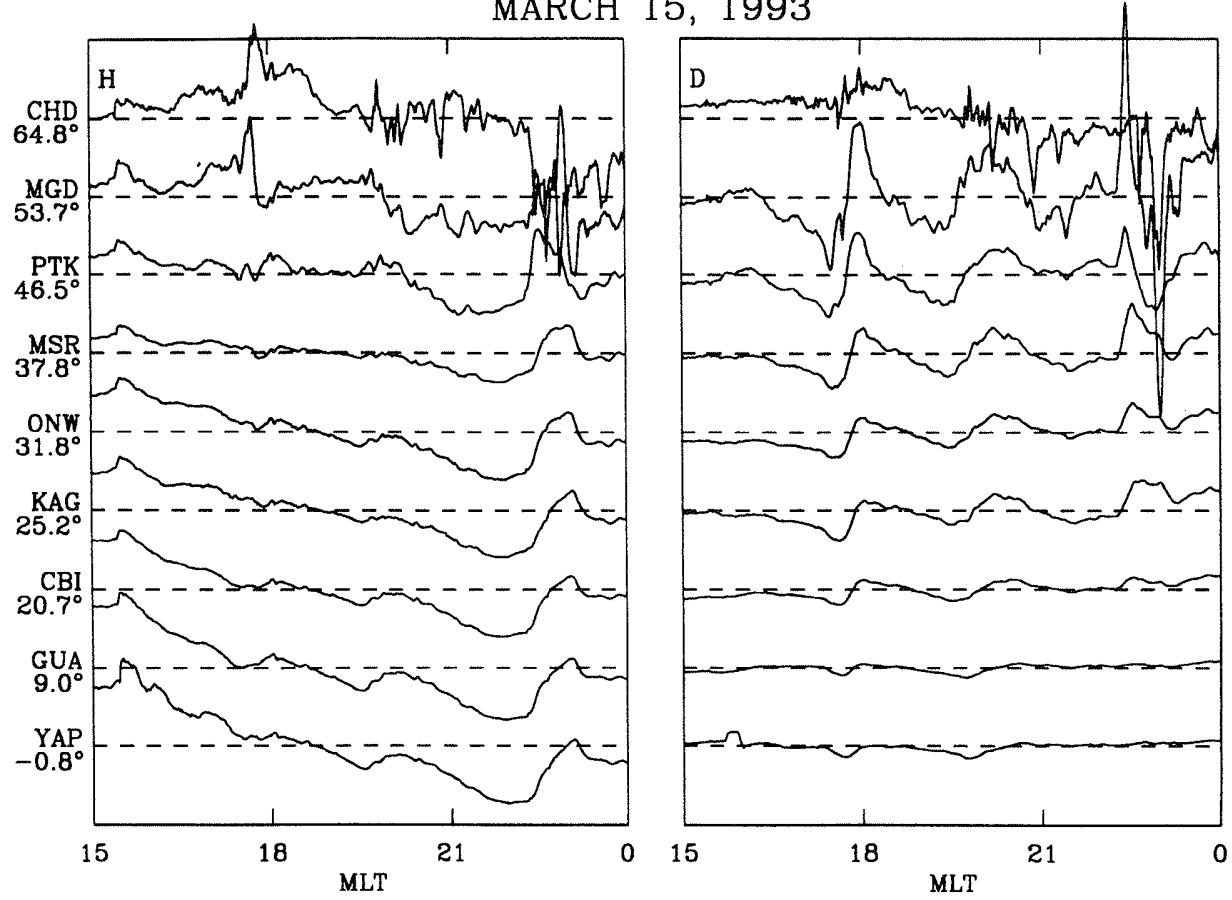

Fig. 4. $\mathrm{H}$ and $\mathrm{D}$ component variations of magnetic field observed at nine stations along the $210^{\circ} \mathrm{MM}$ during the magnetic storm of March 15, 1993.

\section{MAIN PHASE OF MAGNETIC STORM}

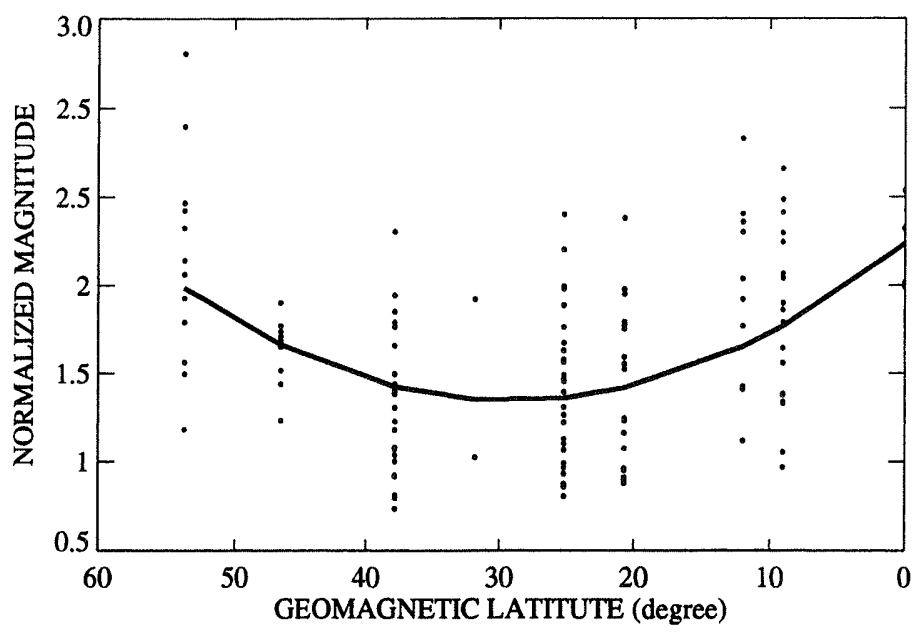

Fig. 5. The statistical dependence of the main phase of magnetic storms on magnetic latitude. The dots indicate the data points and the solid curse is fitted from the data points. 


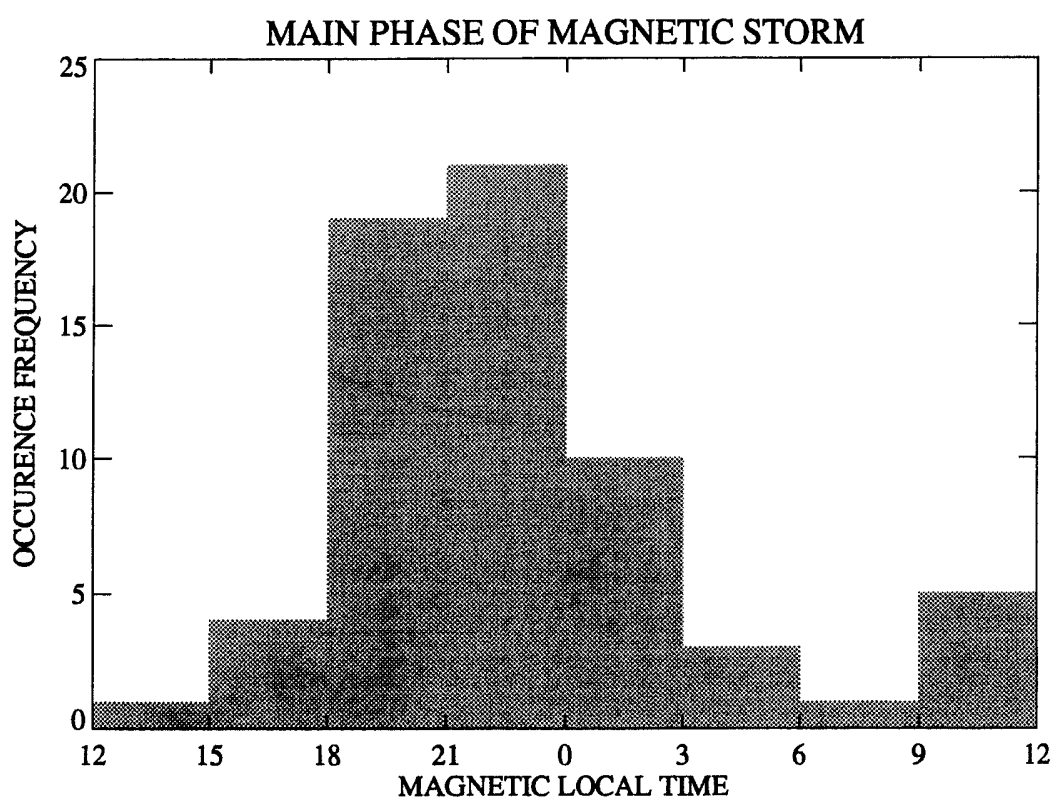

Fig. 6. The statistical distribution of the observable frequency of the main phase along the $210^{\circ} \mathrm{MM}$ stations with magnetic local time.

minimum magnitude of the mian phase is located at about $30^{\circ}$ latitude. The maximum magnetude occurs at the equator. The magnetude at $30^{\circ}$ magnetic latitude decreases to a half of that at the equator. The magnitude at $50^{\circ}$ magnetic latitude is 1.5 times larger than that at $30^{\circ}$. The increase of the magnitude at higher latitudes than $30^{\circ}$ may arise from the westward electrojet and the upward field-aligned currents which causes a negative $\mathrm{H}$ component variation outside the substorm current wedge. In fact, the development of the main phase observed at higher latitudes (e.g. at MGD and PTK) results more from the threedimensional current system at high latitudes than the ring current.

Fig. 6 shows the dependence of the observable frequency of the main phase on magnetic local time. In this statistics, we examine 60 storm events from July, 1990 to June, 1993. A high maximum value of the observable frequency of the main phase occurs in the $21 \sim 0$ MLT sector, whichi is in accordance with maximum observable frequency of the substorm expansion onset (e.g. NAGAI, 1991). This coincidence may be an evidence of the relation between substorms and the magnetic storm.

\section{Theoretical Model}

Sun et al. (1984) calculated $\mathrm{H}$ and $\mathrm{D}$ component variations at six mid-latitude stations during three days produced by the three-dimensional current system at high latitudes. The calculated results are in fair agreement with the observed ones. In that calculation, fieldaligned currents are assumed to flow along the dipole field line. In the present work, the latitudinal dependence of $\mathrm{H}$ and $\mathrm{D}$ perturbations at mid- and low-latitudes produced by the three-dimensional current system are estimated, assuming that the field-aligned currents flow along the field lines in an improved TsYGanENKo's geomagnetic field model (TsYGanENKo, 


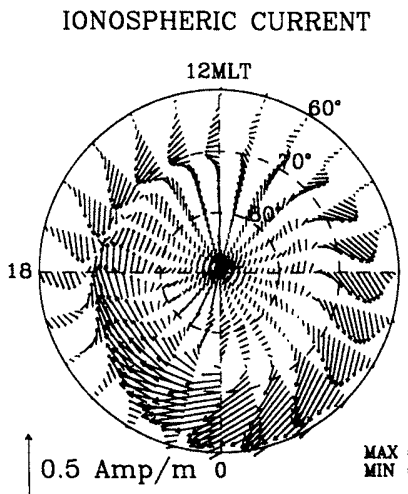

(a)

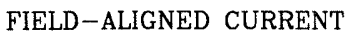

$12 \mathrm{MLT}$

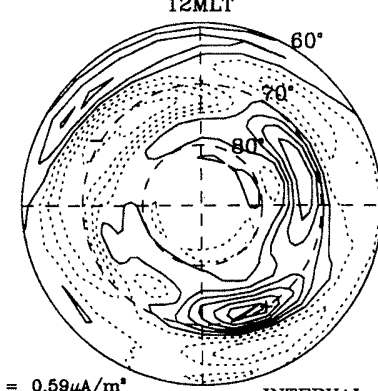

INTERVAL $=0.1 \mu \mathrm{A} / \mathrm{m}^{\mathrm{s}}$
MAGNETIC FIELD

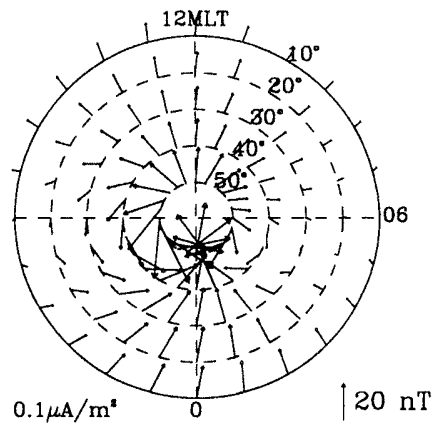

(c)

Fig. 7. (a) and (b) show the average petterns of the distribution of ionospheric current vectors and field-aligned currents for the peak of substorms at high latitudes $\left(60^{\circ} \sim 90^{\circ}\right)$, respectively. (c) shows the magnetic field variations at mid- and low-latitudes $\left(10^{\circ} \sim 50^{\circ}\right)$ calculated by a model of threedimensional current system which is constructed on the basis of Fig. 7 a and $\mathrm{b}$.

1989; STERn, personal communication, 1993). Fig. $7 \mathrm{a}$ and $\mathrm{b}$ show the average patterns of the distribution of ionospheric current vectors and field-aligned currents for the peak of substorms at high latitudes $\left(60^{\circ} \sim 90^{\circ}\right)$, respectively (KAMIDE et al. 1996). In Fig. $7 \mathrm{c}$ the magnetic field variations at mid and low latitudes $\left(10^{\circ} \sim 50^{\circ}\right)$ are calculated from a model of threedimensional current system which is constructed on the basis of Fig. $7 \mathrm{a}$ and b. We take the average over the longitude at different latitudes for positive and negative perturbations in the $\mathrm{H}$ and the $\mathrm{D}$ component, respectively. Then, the mean values at the different latitudes are normalized by the mean value at $10^{\circ}$ magnetic latitude. Fig. 8 shows the calculated latitudical dependence of the positive and the negative perturbation in the $\mathrm{H}$ and the $\mathrm{D}$ component, as well as the statistical results from Fig. 2 for comparison. One can find that the calculated results are in fair agreement with the statistical one.

\section{Summary}

Magnetometer data recorded along the $210^{\circ}$ magnetic meridian stations between July, 1992 and June, 1993 are examined to study the dependence of magnetic bays and the main phase of magnetic storms on magnetic latitude and local time. The results are as follows:

(1) The magnitude of bays in the $\mathrm{H}$ component at mid-and low-latitudes is weakly dependent on magnetic latitude, but the magnitude of bays in the $\mathrm{D}$ component is greatly dependent on the latitude. The statistical formulas of the latitudinal dependence of bays in the $\mathrm{H}$ and the $\mathrm{D}$ component are obtained, as shown in Eq. (1) (4).

(2) The calculated latitudinal profiles of magnetic perturbations of the $\mathrm{H}$ and $\mathrm{D}$ component at the mid-and low-latitudes are in fair agreement with the statistical one.

(3) The peak of the occurrence frequency of bays in the $\mathrm{H}$ component is located at $21 \sim 0$ MLT. Positive bays occur most frequently around the midnight sector; negative bays in the 

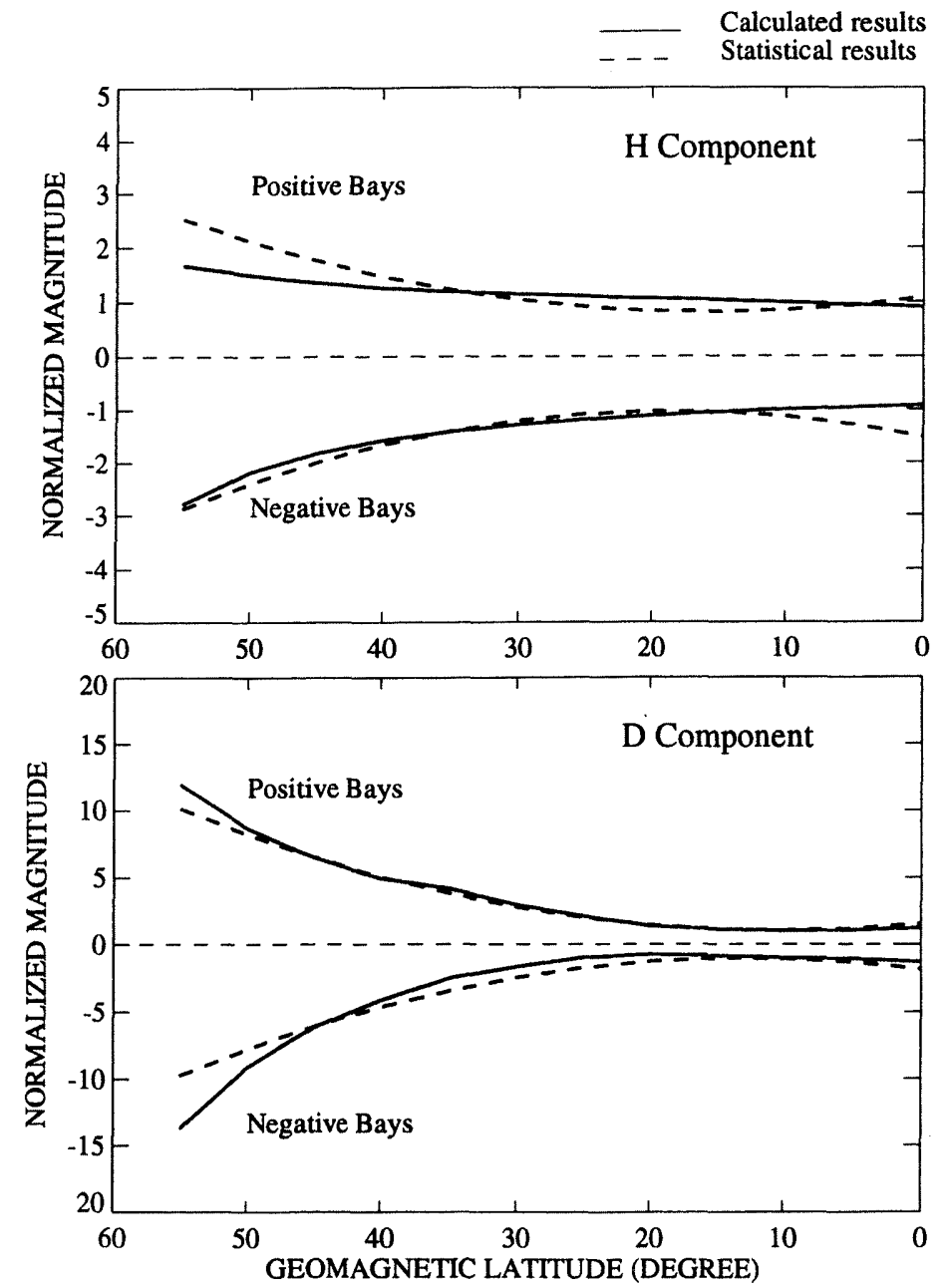

Fig. 8. The calculated and statistical dependence of magnetic bays on magnetic latitude. The solid curves are calculated on the basis on a model of the three-dimensional current system constructed from the ionospheric currents and the field-aligned currents as shown in Fig. $7 \mathrm{a}$ and b. The dashed curves are statistical results as shown in Fig. 2.

evening sector.

(4) The peak of the occurrence frequency of bays in the D component is also located 21 $\sim 0$ MLT. Positive bays most frequently occur in the late evening sector, and negative bays in the early morning sector.

(5) The magnitude of the main phase decrease along the meridian has a minimum which is located at about $30^{\circ}$ magnetic latitude.

(6) The maximum magnitude of the main phase decrease most frequently occurs at $21 \sim 0$ MLT. 


\section{Acknowledgements}

Our sincere thanks go to all the members of the $210^{\circ}$ MM Magnetic Observation Project for their ceaseless support.

\section{References}

AKasofu, S.-I. and S. Chapman (1961): The ring current, geomagnetic disturbance and the VanAllen radiation belts. J. Geophys. Res., 66, 1321.

Akasofu, S.I. and C.-I. Meng (1969): A study of polar magnetic substorm. J. Geophs. Res., 74, 293.

Chapman, S. (1919): An outline of a theory of magnetic storms. Proc. Roy. Soc. London, A95, 61.

Clauer, C. R. and R. L. MCPherron (1974): Variability of mid-latitude magnetic parameters used to characterize magnetospheric substorm. J. Geophys. Res., 79, 2898.

Fukushima, N. (1953): Polar magnetic storms and geomagnetic bays. J. Fac. Sci. Univ. Tokyo Sect. 2, 8, 293 ,

Kamide, Y., B.-H. Ahn, G. K. Corrick, and S.I. Akasofu (1981): Magnetic field of the average substorm current system in middle and low latitude. J Geophys. Res., 86, 821.

KAmide, Y. W. Sun, and S.-I. AkASofu (1995): The average ionospheric electrodynamics for the different substorm phases. J. Geophys. Res., 101, 99.

Mcpherron, R. L., C. T. Russell, and M. P. Aubry (1973): Satellite studies of magnetospheric substorms on August 15, 1968, 9, Phenomenological model for substorms. J. Geophys. Res. 78, 3131.

Meng, C.-I., and S.-I. Akasofu (1969): A study of polar magnetic substorms, 2 Three-dimensional current system. J. Geophys. Res., 74, 4035.

NAGAI, T. (1991): An empirical model of substorm-related magnetic field variations at synchronous orbit, in Magnetospheric Substorm, Geophys. Monogr., ser, vol. 64, p 91, ed. by J. R. Kan, T. A. Potemra, S. Kokubun, T. Ijima, AGU, Washington, D. C.

SilsbeE, H. C., and E. H. Vestine (1942): Geomagnetic bays, their frequency and current system. Terr. Mag. Atmos. Elec., 47, 195.

Sugiura, M. (1964): Hourly values of the equatorial Dst for IGY. Ann. Int. Geophys. Year, 35, Pergamon Press, Oxford, pp9-45.

Sun, W., B.-H., Ahn, S.-I. AKasofu, and Y. Kamide (1984): A comparison of the observed midlatitude magnetic disturbance fields with those reproduced from the high-latitude modeling current system. J. Geophys.Res., 89, 10, 881.

TSYGanenKo, N. A. (1989): A magnetospheric magnetic field model with a warped tail current sheet. Planet. Space Sci., 37, 5.

Yumoto, K., Y. Tanaka, T. Oguti, K. Shiokawa, Y. Yoshimura, A. Isono, B. J. Fraser, F. W. Menk, J. W. Lynn, M. Seto, and 210 MM Mmgnetic Observation Group (1992): Globally coordinated magnetic observations along $210^{\circ}$ magnetic meridian during STEP period; 1 . Preliminary results of low-latitude Pc 3's. J. Geomag. Geoelectr., 44, 261.

Yumoto, K., and the $210^{\circ}$ MM Magnetic Observation Group (1996): The STEP $210^{\circ}$ magnetic meridean network Project. J. Geomag. Geoelectr., 48, 1297. 